\title{
A Comparison of the Effects of Estradiol and 2- and 4-Hydroxyestradiol on Uterine Ornithine Decarboxylase Activity in Immature Rats
}

\author{
Hiroshi Kogo', Donald C. Johnson ${ }^{2}$, Sudhansu K. Dey ${ }^{2}$ and Satoshi Takeo ${ }^{1}$ \\ ${ }^{I}$ Department of Pharmacology, Tokyo College of Pharmacy, 1432-1 Horinouchi, Hachioji, Tokyo 192-03, Japan \\ ${ }^{2}$ Department of Obstetrics and Gynecology and Physiology, Ralph L. Smith Research Center, \\ University of Kansas Medical Center, Kansas City, Kansas 66103, USA \\ Received October 7, 1992 Accepted November 4, 1992
}

\begin{abstract}
Effects of estradiol (E2) and catechol-estrogens (CEs: 2-OHE2 and 4-OHE2) on uterine ornithine decarboxylase (ODC) activity have been compared in immature rats. The intensity of their actions by s.c. $(1 \mu \mathrm{g})$ and intrauterine right-horn (i.u., $25 \mathrm{ng}$ ) injection was in the order of: 4-OHE2 $\geqq \mathrm{E} 2>2-\mathrm{OHE} 2$. Although i.u.-injection of E2 caused an increase in ODC activity in the left (intact)-horn, which was about $60 \%$ that of the right-horn, the effects by CEs were limited only to the right-horn. The results are consistent with the previous view about the order of the potency of 4-OHE2 and 2-OHE2 and also suggest that locally produced CEs may play a role in the physiological functions of the production site.
\end{abstract}

Keywords: Estradiol, 2- and 4-Hydroxyestradiol, Uterine ornithine decarboxylase activity

Estradiol-17 $\beta$ (E2) causes a marked and rapid increase in ornithine decarboxylase (ODC) activity, an enzyme that is involved in polyamine synthesis and participates in the mechanism leading to tissue growth (1), in the immature rat uterus within a few hours of hormone treatment (2). Catechol estrogens (CEs), 2-hydroxyestradiol (2OHE2) and 4-hydroxyestradiol (4-OHE2), are natural metabolites of E2 formed by aromatic hydroxylation of primary estrogens at either the 2 or 4 position (3). The importance of CEs formed by their target tissues in the production of the estrogenic response has been noted (4). In the 1980s, the estrogenic intensity of CEs has been compared with primary estrcgens for many physiological events involved in reproductive activity: increase of uterine weight (5), stimulation of prostaglandin (PG) production in the uterus (6) and the blastocysts (7), induction of uterine progesterone receptors (5) and implantation (8), and stimulation of estrogen specific-induced protein synthesis in the uterus (5). However, regrettably, there have been no comparative study on the effects of E2 and CEs, by systemic and local injection, on uterine ODC activity. Therefore, we have evaluated the effects and the potency of E2 and CEs on uterine ODC activity in immature female rats.

Immature (26 days of age) Wistar strain female rats were used. They were housed 5-10/cage, with free access to tap water and laboratory chow. Room lights were on from 07:00 to 19:00 hr daily. The temperature and humidity were controlled at $23 \pm 1{ }^{\circ} \mathrm{C}$ and $55 \pm 5 \%$, respectively. E2 (Sigma Chemical Co., St. Louis, MO, USA) and CEs (2-OHE2 and 4-OHE2: Steraloids, Inc., Wilton, NH, USA) were dissolved in sesame oil or in $0.2 \%$ alcohol$0.15 \mathrm{M} \mathrm{NaCl}$ solution (alcohol-saline). Each hormone was given to rats by a single s.c. $(1 \mu \mathrm{g} / 0.1 \mathrm{ml}$ oil)- or i.u. ( $25 \mathrm{ng} / 12.5 \mu \mathrm{l}$ alcohol-saline)-injection. Rats were decapitated $4 \mathrm{hr}$ after the treatment. Uteri were removed at the upper site of the uterine cervix, trimmed, weighed and stored in liquid nitrogen until ODC analysis. Intra-uterine injection was carried out with the aid of light ether anesthesia. Only the uterine right-horn was exposed through a dorsolateral incision, and the ovarian end of the uterus was gently held with small forceps. Twenty-five nanograms of each of the hormones in $12.5 \mu \mathrm{l}$ of alcoholsaline was injected into the uterine right-horn lumen with a Hamilton microsyringe. Control animals were given the vehicle alone to the right-horn lumen. The left-horn remained intact. Removed uteri were divided into the leftand right-horn at the cervix, weighed on a torsion balance and quickly stored in liquid nitrogen. For ODC analysis, uteri were homogenized at $4{ }^{\circ} \mathrm{C}$ in 25 volumes (by weight) of $0.05 \mathrm{M}$ phosphate buffer, $\mathrm{pH} 7.2$, containing $5 \mathrm{mM}$ dithiothreitol, $10 \mathrm{mM}$ EDTA, $5 \mathrm{mM} \mathrm{NaF}$ and $1 \mathrm{mM}$ 
Table 1. Relative effects of estradiol and 2- and 4-hydroxyestradiol by a single s.c.-injection in stimulating uterine weight and ODC activity in immature female rats

\begin{tabular}{lcc}
\hline & $\begin{array}{c}\text { Uterine weight } \\
(\mathrm{mg})\end{array}$ & $\begin{array}{c}\text { Uterine ODC activity } \\
\text { (pmoles }{ }^{14} \mathrm{C} / \mathrm{mg} \text { protein/hr) }\end{array}$ \\
\hline Control & $46 \pm 1.8$ & $3 \pm 0.6$ \\
E2 & $62 \pm 2.9^{* * *}$ & $289 \pm 24.4^{* * * *}$ \\
2-OHE2 & $68 \pm 7.2^{* * *}$ & $217 \pm 19.7^{* * *}$ \\
4-OHE2 & $68 \pm 5.1^{* * *}$ & $338 \pm 23.6^{* * *}$ \\
\hline
\end{tabular}

The uterus was excised from rats at $4 \mathrm{hr}$ after a single s.c.-injection of $1 \mu \mathrm{g}$ of estradiol (E2), 2-hydroxyestradiol (2-OHE2) or 4-hydroxyestradiol (4-OHE2). Results are expressed as the mean \pm S.E. of nine rats. ${ }^{* * *} \mathrm{P}<0.001$ : significantly different from the control. ${ }^{\#} \mathrm{P}<0.05$ and ${ }^{* *} \mathrm{P}<0.01$ : significantly different from the 2-OHE2treated group.

PMSF. Following centrifugation at $4^{\circ} \mathrm{C}$ for $30 \mathrm{~min}$ at $15,000 \times g$, the supernatants were assayed for ODC activity utilizing $0.25 \mu \mathrm{Ci}$ of $\mathrm{DL}-\left(1-{ }^{14} \mathrm{C}\right)$-ornithine $(1.6$ $\mathrm{GBq} / \mathrm{mmol}$ : New England Nuclear Corporation), by the method described by Johnson and Sashida (9), with minor modification. ODC activity was expressed as pmoles ${ }^{14} \mathrm{C} / \mathrm{mg}$ protein $/ \mathrm{hr}$. Student's $t$-test (two-tailed) was used to assess the significance of a difference between mean values. $P$ values less than 0.05 were considered to indicate a significant difference.

Table 1 compares the effects of E2, 2-OHE2 and 4OHE2 administered by a single s.c.-injection $(1 \mu \mathrm{g})$ on uterine weight and ODC activity in immature rats. Uterine weight showed a clear increase $4 \mathrm{hr}$ after one shot of each estrogen. However, all three estrogens showed a similar effect. Uterine ODC activity was also markedly activated by treatment with each of the hormones and the intensity of their actions was in the order of: 4OHE2 $>$ E2 $>2$-OHE2. The activity increase by 4-OHE2 and that by $\mathrm{E} 2$ were both significantly higher than that by 2-OHE2. Next, we examined the effects of $E 2$ and CEs on uterine weight and ODC activity in the left- and righthorn by a single i.u.-injection ( $25 \mathrm{ng}$ ) into the uterine right-horn lumen in immature rats (Fig. 1). Administration of 4-OHE2 or 2-OHE2 (but not E2) into the uterine right-horn lumen caused a significant increase in uterine weight of the right-horn (R) compared to that of the lefthorn (L) in each group (Fig. 1A). As in the results in Table 1, the stimulatory effect of the three estrogens on the uterine weight of $\mathbf{R}$ was almost the same. As shown in Fig. 1B, each estrogen and vehicle alone clearly activated the ODC activity in $\mathrm{R}$ compared to that in $\mathrm{L}$. In addition, the ODC activity increased by all three estrogens was also significantly higher than that in $\mathbf{R}$ of the control group. However, administration of $\mathrm{E} 2$ into $\mathrm{R}$ resulted in a substantial activation in ODC activity not only in $R$, but also
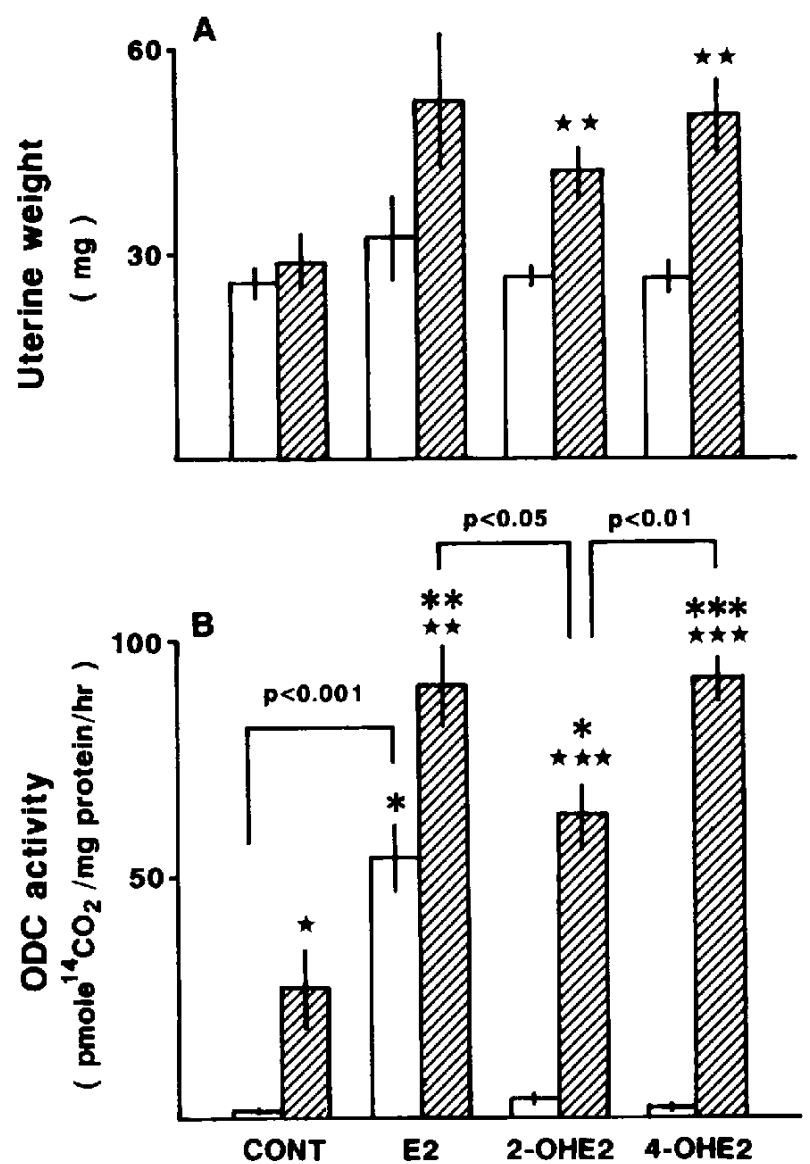

Fig. 1. Difference in the local effects of estradiol and 2- and 4hydroxyestradiol injected into the right-horn on weight (A) and ODC activity (B) in the left- and right-horn of the uterus in immature rats. The uterus was excised $4 \mathrm{hr}$ after injection of each hormone. Each value shows the mean \pm S.E. of four animals. Twenty-five nanograms of each estrogen in $12.5 \mu \mathrm{l}$ of $0.2 \%$ alcohol-saline was injected into the uterine right-horn lumen. Control (CONT) rats were given the vehicle alone to the right-horn. $\star P<0.05, \star \star P<0.01$ and $\star \star \star \mathrm{P}<0.001$ vs. left-horn in each group; ${ }^{*} \mathrm{P}<0.05,{ }^{*} \mathrm{P}<0.01$ and ${ }^{* * *} \mathrm{P}<0.001$ vs, right-horn in the control group. $\square$ : Left-intact horn, $\mathbb{Z}:$ Right-injected horn.

in $\mathrm{L}$. The activity in $\mathrm{L}$ was about $60 \%$ of that in $\mathrm{R}$ and the activity was significantly higher as compared to $\mathrm{L}$ $(\mathrm{P}<0.001)$ and $\mathrm{R}(\mathrm{P}<0.05)$ of the control group. In contrast, the enhanced activities by 4-OHE2 and 2-OHE2 were limited to only the $R$. The levels of ODC activity in the 4-OHE2 and E2 groups were considerably higher than those in the 2-OHE2 group. The intensity of their actions on ODC activity in $\mathrm{R}$ activated by the i.u.-injection of each hormone was 4-OHE2 $=\mathrm{E} 2>2-\mathrm{OHE} 2$.

The result that the effect of 4-OHE2 on ODC activity was more potent than that of 2-OHE2 was consistent with the information seen in other estrogenic responses $(5-7)$. However, some difference was seen between E2 and CEs; 
E2 $>4-O H E 2$ for the induction of uterine progesterone receptors (5) and implantation (8), and 2-OHE2>E2 for PG production in the uterus (6) or the blastocyst (7). The clearance rate of primary $\mathrm{E} 2$ and $C E$ s has been reported to be 1:4:11 for E2, 4-OHE2 and 2-OHE2 (10). Considering this rapid degradation and clearance of CEs, both systemic s.c.- and local i.u.-administrations were adopted in the present study. Despite a similar tendency in the relative effects of each estrogen on ODC activity of the s.c.and the i.u.-injection, the levels induced by the i.u.-injection were lower than those by the s.c.-injection. There is a possibility that the amount of the hormone administered (2) and/or the time after hormone treatment (11) required to cause a maximal response are associated with the low levels in the ODC activity induced by the i.u.-injection. It has been reported that the relative potencies of E2 and CEs on the synthesis of estrogen-specific induced protein (5) and the release of luteinizing hormone (LH) (12) differ in vivo and in vitro. However, in the present study, the potencies of E2 and CEs to affect ODC activity hardly differed between the s.c.- and i.u.-injections. The basal activity of ODC is generally low (13), and it was activated by the vehicle alone in R (Fig. 1B). The ODC activity is quickly raised by administration of hormone and then rapidly declines from its peak levels (11). Furthermore, uterine ODC activity is characterized as one of the most sensitive indicators of early estrogen-induced uterine responses $(2,14)$. Therefore, we believe that the reactivity of estrogen for uterine ODC activity may result in a substantial difference in other responses like specific-induced protein synthesis and $\mathrm{LH}$ release. In addition, the conversion of E2 injected into $R$ to CEs may, at least partly, participate in the elevation in the ODC activity in L, although the conversion rate of $\mathrm{E} 2$ to $\mathrm{CEs}$ has not yet been estimated. Indeed, Bunyagidj and McLachlan have recently shown that the mouse uterus causes the preferential production of 4-OHE2 and 2-OHE2 by estrogen $2 / 4$ hydroxylase in the presence of relatively less deactivation by catechol-o-methyltransferase (15). Their finding and our results by i.u.-injection, shown in Fig. 1, suggest the possibility of the local formation of CEs from E2 and of a local regulatory role of CEs generated in situ in the physiological functions of the rat.

\section{REFERENCES}

1 Tabor, C.W. and Tabor, H.: 1,4-Diamino (putrescine), spermidine, and spermine. Annu. Rev. Biochem. 45, 285-306 (1973)

2 Kaye, A.M., Icekson, I. and Lindner, H.R.: Stimulation by estrogens of ornithine and $S$-adenosylmethionone decarboxylase in the immature rat uterus. Biochim. Biophys. Acta 252, $150-159$ (1971)

3 MacLusky, N.J., Naftolin, F., Krey, L.C. and Franks, S.: Catechol estrogens. J. Steroid Biochem. 15, 111-123 (1981)

4 MacLusky, N.J., Barnea, E.R., Clark, C.R. and Naftolin, F.: Catechol estrogens and estrogen receptors. In Catechol Estrogens, Edited by Merrian, G.R. and Lipsett, M.B., pp. 151-165, Raven Press, New York (1983)

5 Franks, S., MacLusky, N.J. and Naftolin, F.: Comparative pharmacology of oestrogens and catechol oestrogens: actions on the immature rat uterus in vivo and in vitro. J. Endocrinol. 94, $91-98$ (1982)

6 Kelly, R.W. and Abel, M.H.: A comparison of the effects of 4catechol oestrogens and 2-pyrogallol oestrogens on prostaglandin synthesis by the rat and human uterus. J. Steroid Biochem. 14, 787-791 (1981)

7 Pakrasi, P.L. and Dey, S.K.: Catechol estrogens stimulate synthesis of prostaglandins in the preimplantation rabbit blastocyst and endometrium. Biol. Reprod. 29, 347-354 (1983)

8 Kantor, B.S., Dey, S.K. and Johnson, D.C.: Catechol estrogen induced initiation of implantation in delayed implanting rat. Acta Endocrinol. 109, 418-422 (1985)

9 Johnson, D.C. and Sashida, T.: Temporal changes in ovarian ornithine decarboxylase and cyclic AMP in immature rats stimulated by exogenous or endogenous gonadotrophins. J. Endocrinol. 73, 463-471 (1977)

10 Ball, P., Emons, G., Kayser, H. and Teichmann, J.: Metabolic clearance rates of catechol estrogens in rats. Endocrinology 113, $1781-1783$ (1983)

11 Kaye, A.M., Icekson, I., Lamprecht, S.A., Gruss, R., Tsafriri, A. and Lindner, H.R.: Stimulation of ornithine decarboxylase activity by luteinizing hormone in immature and adult rat ovaries. Biochemistry 12, 3072-3076 (1973)

12 Emons, G., Knuppen, R., Ball, P. and Catt, K.J.: Effects of structural changes in the A-ring of the estradiol molecule on its potency in sensitizing cultured pituitary cells to gonadotrophin releasing hormone. Neuroendocrinol. Lett. 4, 185 (1982)

13 Janne, J., Poso, H. and Raina, A.: Polyamines in rapid growth and cancer. Biochim. Biophys. Acta 473, 241-293 (1978)

14 Katzenellenbogen, B.S. and Gorski, J.: Estrogen actions on synthesis of macromolecules in target cells. In Biochemical Actions of Hormones, Edited by Litwack, G., Vol. 3, pp. 187-243, Academic Press, New York (1988)

15 Bunyagidj, C. and Mclachlan, J.A.: Catechol estrogen formation in mouse uterus. J. Steroid Biochem. 31, 795-801 (1988) 